\title{
CONOTAÇÃO FORMATIVA DA LINGUAGEM EM LUDWIG WITTGENSTEIN
}

\author{
José Sílvio de Oliveira ${ }^{1}$
}

\begin{abstract}
RESUMO
Analisar a conotação formativa da linguagem quando travada pelo conhecimento metafísico é a meta proposta da investigação, tendo como referência a filosofia de Ludwig Wittgenstein (1889-1951). Bem sabemos, em relação ao conhecimento, desde a Grécia antiga ou medieval e, ainda hoje, grande parte dos filósofos insistem em construir um sistema de proposições universalmente válidas. Para tanto, é necessário, antes de tudo, fazer uma exposição histórica das questões epistemológicas que levaram esse filósofo a entender que a linguagem é um caminho seguro e pode oferecer uma solidez não apenas à linguagem, mas também ao trabalho da filosofia. $E$ assim, em seguida, debruçar à demonstração das razões que nos levam a entender que as pretensões filosóficas nem sempre são legítimas como assim pensavam os tradicionais da filosofia. Digamos de passagem, nossa reflexão é trivial na esfera filosófica. Alavancado metodologicamente por uma trilha analítica, o trabalho se divide em dois momentos, o primeiro, aborda questões sobre o conhecimento metafísico e a aparente pretensão finalística de um suposto conhecimento metafísico, num segundo momento, trata-se de investigar a linguagem na dimensão dos jogos de linguagem. As fontes principais de investigação são: Tractatus Logico-Philosophicus (1968) e, Investigações Lógicas (1999).
\end{abstract}

Palavras-chaves: Metafísica. Linguagem. Wittgenstein.

\section{ABSTRACT}

To analyze the formative connotation of the language when caught by the metaphysical knowledge is the goal proposed in this research, whose reference is the philosophy of Ludwig Wittgenstein (18891951). It's well known, regarding knowledge from ancient or medieval Greece and even today; that most philosophers insist on building a system of universally valid propositions. Therefore, it is necessary, first of all, to make a historical exhibition of epistemological issues that led this philosopher to comprehend that language is a safe way and that it can provide a kind of solidity not only to the language but also to the philosophical work. Thus, soon after, to address the statement of reasons that can lead us to the comprehension that philosophical claims are not always legitimate as traditional philosophers used to believe them. As to say, our reflection is trivial in the philosophical sphere. Leveraged methodologically by an analytical track, the work is divided in two stages, the first one addresses issues of metaphysical knowledge and the apparent purposive claim of an alleged metaphysical knowledge, the second one is to investigate the language in the dimension of language-games. The main sources of researching are: Tractatus Logico-Philosophicus (1968) and Logical Investigations (1999).

Keywords: Metaphysics. language. Wittgenstein.

\section{INTRODUÇÃO}

Analisar a linguagem em Ludwig Wittgenstein (1889-1951) e interrogá-la, sem dúvida, é perguntar a conotação de seu uso. A linguagem, acima de tudo, é uma criação e convenção da humanidade, em si é formativa. Mas, como disso saber? Tudo está no mundo,

\footnotetext{
1 Professor de Filosofia da Educação da Unidade Acadêmica de Educação da Universidade Federal de Jataí, GO, coordenador do Grupo de pesquisas, Filosofia e Educação - paideia aristotélica e paideia Tomista. Editor da Revista Itinerarius Reflectionis, Doutor em Educação pela UFSCar, E-mail: oliveirajose354@gmail.com.
} 
Wittgenstein explica bem no início do Tractatus: "O mundo é a totalidade dos fatos, não das coisas [...]." (TL, 1-1.1, 1968, p.55). Quando ele expressa que o mundo é a totalidade dos fatos e não das coisas, em certo sentido, está ele, colocando em xeque toda a teoria tradicional do conhecimento. Não é nenhuma novidade afirmar que o homem criou a cultura, a escrita, o alfabeto, a roda, inventou tudo aquilo que se constitui como cultura. Os contemporâneos de Wittgenstein, o filósofo francês Gilles Deleuze (1925-1945) e também o psicanalista Félix Guattari, (1930-1992), escreveram: "Nada é mais doloroso, mais angustiante do que um pensamento que escapa a si mesmo, ideias que fogem e desaparecem; apenas esboçadas, já corroídas pelo esquecimento ou precipitadas em outras, que também não dominamos." (2004, p.259). Em 1918, no prefácio do Tractatus, o filósofo austríaco escreve:

Caso meu trabalho tenha valor, ele será duplo. Primeiramente porque exprimem pensamentos, valor que será tanto maior quanto melhor forem expressos. Nisto estou consciente de estar muito aquém do possível, [...] No entanto, a verdade dos pensamentos comunicados aqui me parece intocável e definitiva, de modo que penso ter resolvido os problemas no que é essencial. Se não me engano, o segundo valor desse trabalho é mostrar é mostrar quão pouco se consegue quando se resolvem tais problemas (1968, p.54).

Wittgenstein sabe muito bem o problema que está diante dele, não é uma questão simples, fácil de resolver, portanto, conhece a realidade dos pensamentos, eles "[...], são por assim dizer, vagos, e obscuros [...]". (TL 1968, p.77). Logo, a filosofia wittgensteiniana é em si, elucidativa, portanto, formativa, no caso, propriamente linguística. A análise filosófica desse filósofo reduz o sentido metafísico da linguagem e a coloca no plano coloquial do mundo, ao mesmo tempo, modifica a tarefa filosófica. Nascia um novo contexto para o âmbito da filosofia moderna. Podemos assim afirmar, os filósofos analíticos e os da linguagem deram uma nova roupagem à filosofia. Ao enfrentar a questão da linguagem, especificamente, do conhecimento propositivo que identifica o conhecimento do fato e da coisa, John, L. Austin (1911 - 1960), em Philosophical Papers, em certo sentido, entendeu que isso não é senão uma questão de uma união de cláusulas sem sustentação, logo, resultado de uma relação semelhante ao casamento - apenas uma conveniência. Afirmar que, o fato em si é uma coisa, só pode ser uma questão das cláusulas conectadas ao dicionário.

Fact is wedded to that-clauses' with the evidence of the Dictionary. If it is indeed so wedded, it leads, I fear, a double life. It was not born in wedlock, its marriage was a marriage of convenience and it continues to lead a flourishing bachelor existence. (1970, p.163)

Quando Danilo Marcondes investiga a filosofia de Wittgenstein, para ele, ela não é senão: "[...] um processo de clarificação do sentido da nossa experiência através do exame da linguagem, do estabelecimento das regras que tornam esse uso possível, do contexto em que se dá." (2004, p.43). A crítica wittgensteiniana não é uma crítica da linguagem 
propriamente dita ou dos jogos de linguagem, o que já seria suficientemente uma crítica acertadíssima, entretanto, é uma crítica que perpassa a gênese, seu desenvolvimento e a constituição da linguagem da civilização ocidental no âmbito da filosofia. De modo especial, em Investigações Filosóficas, o método analítico de Wittgenstein consiste num trabalho amplo de decomposição das mais variadas formas do encadeamento complexo de proposições que constituem o mundo da linguagem e, portanto, a tarefa da filosofia não é senão aclarar a tonalidade desse processo; ressalto aclarar não tão-somente a forma gramatical, pois, sua investigação desvenda e desamarra as artimanhas metafísicas que amarraram e travaram seu uso.

Embora seja uma questão bastante conhecida na filosofia, é preciso esclarecer previamente a famosa distinção entre o primeiro e o segundo Wittgenstein e, sobretudo, o seu não estilo filosófico. Seus escritos são densos e complexos e não têm um estilo modelado. Wittgenstein escreve por aforismos, termo transmutado da língua grega - aforismos aphorizein, cuja semântica grega significa separação, delimitação. Isto é, para exprimir seus pensamentos, Wittgenstein separa, delimita a frase ou as proposições - ao compor cada proposição ele separa uma das outras, são balizadas e, sobretudo, sequencialmente numeradas. Assim, de forma generalizada, quando o leitor está desatento, os escritos wittgensteinianos parecem desorganizados e desconexos, o que em si está em acordo com seu não estilo, logo, sua filosofia não é sistematizada, pronta e acabada, mais que isso, o significado das proposições, das frases, dos nomes, do próprio conceito, não é e nem poderia ser algo fixo, retido e travado.

Afirmado isso, passamos à clássica distinção entre o primeiro e o segundo Wittgenstein. A obra que caracteriza sua primeira fase é publicada em 1921, intitulada Tractatus Logico-Philosophicus. Nesta obra, o pensamento filosófico de Wittgenstein se aproxima das obras de três renomados filósofos analíticos, Gottlob Frege (1848-1925), Bertrand Russell (1872-1990) e George Edward Moore (1873-1958). Neste primeiro Wittgenstein, a preocupação investigativa fica amarrada às questões da lógica gramatical. A questão está em saber se a proposição é verdadeira ou falsa. Nesta perspectiva, expressa Wittgenstein: "A linguagem veda o pensamento; [...]." (TL, 4.002, 1968, p.70). Isto significa que, a aparência em que a linguagem externamente é utilizada, seja no campo científico ou no senso comum, fica circunscrita e amarrada de tal forma que é impossível inferir outra forma de pensamento subjacente, exceto o que ali foi produzido. Logo, a linguagem engana, disfarça, veda e produz os mais diferentes equívocos.

Mas, é exatamente no segundo, mais especificamente na obra escrita em 1929, intitulada, Investigações Filosóficas, que a linguagem passa ter uma conotação de não unificação; em outros termos, a linguagem, distintamente dos escritos do Tractatus LogicoPhilosophicus, ganha uma dimensão de pluralidade e de multiplicidade. Para Wittgenstein, em Investigações Filosóficas, a linguagem é uma questão não singular, ela é diversa e múltipla. 
Sobre esta fase de Wittgenstein, Danilo Marcondes afirma que:

A linguagem não é mais considerada tomando como base a forma lógica da proposição a partir da qual se determina sua relação com o real, isto é, sua verdade ou falsidade. Podemos dizer que, até certo ponto, nas Investigações a noção de linguagem se dissolve, pulveriza-se em uma multiplicidade de 'jogos de linguagem', que se definem como 'um todo, constituindo de linguagem e das atividades a que está interligada.' (2004, p.41).

Em Investigações Filosóficas, Wittgenstein estuda as inúmeras espécies de frases: umas conotam o comando, outras denotam a pergunta, outras ainda indicam afirmações. Se em Tractatus a noção de linguagem, em certo sentido, tinha uma dimensão transcendental, em Investigações, a conotação da linguagem remete explicitamente a uma análise social, pública, cultural e pragmática, logo, é necessário investigar seus efeitos no mundo, na cultura, portanto, na vida cotidiana em que ela está engendrada.

Desde os pré-socráticos (VIII-VI a. C.) até a baixa Idade Média, a linguagem permaneceu imóvel, sempre encoberta pela nuvem dos pressupostos da metafísica, e não seria diferente. $O$ primeiro grande problema enfrentado nestes termos se deu com a questão dos universais, mais especificamente com o problema do nominalismo. Esse foi entendido pela Igreja como heresia, e, portanto, acabou bem antes mesmo de iniciar. Findando o medievo, em 1300, ao seu modo, Guilherme de Ockham (1285-1347) detonou e desmoronou com sua famosa navalha o problema dos universais. O estudo de Guilherme de Ockham, ao mesmo tempo desconhecido, constata um acontecimento ímpar na história, "[...] o de que a crítica interna feita contra ela mesma pelo que se chama, com um termo bastante vago, de filosofia escolástica, provocou sua ruína bem antes da filosofia moderna ter logrado constituirse." (GILSON, 2001, p.797).

A questão da linguagem só voltará ao centro do debate quando, Gottlob Frege, Bertrand Russel, George E. Moore e Ludwig Wittgenstein iniciam uma reação conjunta contra as correntes de inspiração advindas do psicologismo, do idealismo absoluto hegeliano e do transcendental kantiano. Do ponto de vista da analítica da linguagem, Wittgenstein complementa o trabalho de Russell e de Frege. Daí as denominações: por um lado, a semântica clássica ou filosofia analítica da linguagem, de onde emanam os nomes de Russel e Frege; expoentes da escola analítica de Cambridge, juntamente com o primeiro Wittgenstein e, o próprio Círculo de Viena, onde seus representantes principais são Rudolf Carnap (18911970) e Moritz Schlick (1882-1936). Por outro lado, a denominação filosofia da linguagem, entre seus expoentes estão: George E. Moore, o segundo Wittgenstein, e o britânico John Austin, esses, pensadores da escola de Oxford.

Metodologicamente a nossa trilha investigativa é uma trilha amarrada às questões da análise, o trabalho tem o caráter bibliográfico. As fontes principais dessa análise são as duas obras de Ludwig Wittgenstein supracitadas no resumo. A primeira parte aborda a linguagem 
determinada historicamente e oculta no âmbito metafísico. A segunda parte é propriamente uma investigação da conotação formativa da linguagem. Vale ressaltar que não trataremos aqui da filosofia de Wittgenstein, essa não é nossa intenção. As citações e a indicação das referências no texto, necessariamente, terão critérios próprios, uma vez que as obras de Wittgenstein são densas, sobretudo, sequencialmente numeradas; por isso, as citações das obras específicas são diferenciadas das demais citações. Para cada obra específica, utilizarse-ão as seguintes abreviações: para o Tractatus, a expressão (TL) e, para as Investigações, (IF), seguido de ano e página respectivamente.

\section{O HORIZONTE HISTÓRICO}

Para compreender a noção de linguagem em Wittgenstein será necessário retroceder um pouco na história da filosofia e aí, entender o contexto em que a mesma foi engendrada. No âmbito da filosofia, a linguagem sempre apareceu envolta e entrelaçada sobre as amarras da metafísica. Em suma, num conhecimento tipo metafísico. Para Aristóteles (2005), os primeiros filósofos da Grécia antiga consideravam como primeiros princípios, tãosomente, as causas materiais. Contudo, Parmênides (530-460 a. C.), nascido na cidade de Eléia, na região do sul da Magna Grécia, foi o primeiro, nestes termos, a indicar a questão. Escreve ele em Sobre a Natureza:

[...] os únicos caminhos de investigação que há para pensar: um que é, que não é para não ser; é caminho de confiança (pois acompanha a verdade); esse te indico ser caminho em tudo ignoto, pois não poderás conhecer o que não é, não é consumável, nem mostra-lo [...] pois o mesmo é pensar e ser. (FRAGMENTO 2, 2002).

Em outras palavras, o ser é e não pode deixar de ser, e o não ser não é, e não pode ser. Este é para Parmênides o ponto de partida e de chegada para descobrir toda a verdade ou, pelo menos, dela, estar a caminho. Notemos aqui, o filósofo não está se referindo ao sentido prático da linguagem e nem poderia. Os primeiros filósofos não tinham tais preocupações e, em certo sentido, isso não estava claro na cabeça deles. Independentemente desta situação, eles queriam saber sobre os limites e possibilidades do conhecimento. O ser que Parmênides pensava, era um ser imóvel, incriado, imutável e único. Para ele, este ser existia em si e per si, e Ihe foi revelado pela divindade; lê-se no Fragmento primeiro: "Os corcéis que me transportam, tanto quanto o ânimo me impele, conduzem-me, depois de me terem dirigido pelo caminho famoso da divindade, que leva o homem sabedor por todas as cidades." (PARMÊNIDES, 2002). Esta suposta verdade intelectual que pensou Parmênides é o critério que fundamentava toda a verdade e, simbolicamente foi uma revelação dos deuses, da divindade. Sobre Parmênides e seu ser único, incriado e imóvel, Friedrich Nietzsche (18441900) enfatiza: 
A caminho, depara com Heráclito - encontro infeliz! Ele, para quem tudo assentava na mais estrita cisão entre o ser e o não-ser, devia odiar de modo profundo, justamente agora, o jogo das antinomias de Heráclito: uma máxima como <<somos e não somos ao mesmo tempo >>, << O ser e o não-ser são, ao mesmo tempo, a mesma coisa e não a mesma coisa >>; uma frase que voltava a obscurecer e a emaranhar tudo o que ele acabara de esclarecer e de desvendar, irritou-se profundamente: $<<$ Fora com os homens >> gritava ele, <<que parecem ter duas cabeças e que nada sabem. >> Neles, tudo flui e também o seu pensamento. (2009, p.64).

Se o ser era a única verdade para Parmênides, em Heráclito o ser era o próprio devir O ser de Parmênides é único, não poderia haver outro, caso assim fosse, não seria único. Da mesma forma, ele pensou: o ser é imóvel, se assim não o fosse poderia vir a ser e, finalmente, o ser para ele é incriado, pois, se não fosse, poderia ser criado ou pelo ser, ou pelo não ser. Fora disso tudo é contradição, aberração, incoerência, incongruência, portanto, absurdo. Neste horizonte trágico dos gregos podemos perceber, claramente, a linguagem em Parmênides decididamente está travada e vedada, como pensou Wittgenstein (TL 4002, 1968, p.70). Deste contexto filosófico decorreram inúmeras tentativas de conciliar tais proposições. Por exemplo, quando alguém afirma que uma laranja não é um macaco, certamente está afirmando que existe o não ser, mas isso é desconcertante. Tudo isso é muito estranho para nós, pode parecer desconexo, uma vez que o tempo verbal 'é', sem dúvida, negado na proposição e não no sentido de existência, mas isso nos primórdios da filosofia, não estava distinto. Ao afirmar que a laranja não é um macaco não significa negar a existência da laranja, mas, apenas negar a ela o predicado de ser macaco. Estamos atribuindo à laranja apenas um qualitativo, e não o existencial.

A partir dessas questões e dificuldades, a filosofia logrou, desde as suas origens, construir um sistema de proposições universalmente válidas ou, mais especificamente, em crenças justificadas. Seja em Platão (428-347) como em Aristóteles (384-322). Tanto em Agostinho (354-430) como em Tomás de Aquino (1225-1274). Seja também na intuição de René Descartes (1596-1650), como nos pensamentos distintos de Baruch Espinoza (16321677) ou de Gottfried Leibniz (1646-1716). Além de outros, aumentam a lista Friedrich Hegel (1770-1831), Immanuel Kant (1724-1804), Edmund Husserl (1859-1938), todos esses e muitos outros, em detrimento da linguagem, não fazem outra coisa senão alargar o campo metafísico.

Ainda na Grécia clássica, Platão tenta resolver o conflito de Parmênides e de Heráclito, entretanto, no âmbito metafísico. Para resolver isso, Platão cria dois mundos para entender todas essas aporias - dúvidas e hesitações. Portanto, cria os dois conhecidos mundos: o sensível e o inteligível. A questão do conhecer não é algo novo, Platão procura distinguir o que é meramente opinião (doxa) do conhecimento (epistéme). Nesta perspectiva, ele tenta conciliar a unidade do ser com a pluralidade dos entes, a imutabilidade do ser com o movimento e o próprio conhecimento. Tudo isso é objeto de conhecimento, mas, deriva do 
Uno. Lê-se em República:

Ora, o que comunica a verdade aos objetos conhecidos e ao sujeito cognoscente a faculdade de conhecer, podes afirmar que é a ideia do bem; é a fonte primitiva do conhecimento e da verdade, tanto quanto estes podem ser conhecidos; mas, por mais belos que sejam ambos, o conhecimento e a verdade, se admitires que muito mais belo é esse outro elemento - a ideia do bem- terás pensado com acerto. (2000, p.313).

A ideia de bem que Platão pensou é, de certo modo, a ideia das ideias, ela é o princípio supremo, dela, deriva tudo, com ela, tudo adquire valor e inteligibilidade: é soberana. Podemos dizer que Platão mora no realismo das ideias. Esta ideia, portanto, é a unificação do múltiplo. Esta é uma realidade metafísica. Por seu turno, Aristóteles, não voa tão alto, ele não mora nas ideias, nem no realismo dessas, procura resolver o problema aqui no mundo! E ele reconsidera e redireciona sua metafísica para o plano da realidade. A imutabilidade, a unicidade, a multiplicidade, o movimento, têm causas nas próprias coisas. Ele procura aqui no mundo as causas primeiras. Por isso, a metafísica para ele é a ciência que busca a causa primeira de tudo.

O nome 'metafísica' foi empregado por Andrônico de Rodes para designar os livros de Aristóteles que tinha disposto 'depois dos de filosofia natural' (tà metà physikà). Este rótulo, em forma abreviada e substantivada, passou a ser o nome oficial deste saber primeiro e fundamental. Aristóteles, ao invés, chamava-a 'filosofia primeira' ou 'teologia', em oposição à 'filosofia segunda' ou física. (SILVA, 1994, p.13)

Para Aristóteles, essa é a ciência que investiga o ser. A metafísica aristotélica estuda o ser enquanto ser. "Esta ciência (epistéme), pela qual aspirava em toda sua obra, expressa um 'saber fundado,' [...] O lugar próprio da verdade (científica) é o 'ser assim como ele é'. O que quer dizer concretamente: 'aquilo que é enquanto é', (on hê on, ens qua ens) [...] (SILVA, 1994, p.74). Pela metafísica, ele procura resolver as causas últimas aqui em baixo no mundo! Além de outras, três são as categorias que ele propõe para resolver as questões: o ato, a potência, matéria e forma. Se Parmênides diz que o ser é único, então como conciliar a pluralidade dos entes? Para Aristóteles, todos os entes são constituídos de matéria e forma, potência e ato e, portanto, em outros termos, podemos expressar que existe em cada ente algo que muda no tempo, ou mais precisamente, o ato, e algo que permanece, isto é, a potência. Portanto, é possível conhecer os entes, exatamente porque algo neles permanece imóvel. O ser que pensou Aristóteles não pode ser entendido numa única realidade, o ser necessita ser entendido em muitos sentidos. Para ele, 'ser' é também uma realidade analógica, o ser é em si, isto é, em sua essência, per si - necessariamente é, mas, podemos notar também, ele o é em acidentes - per accidens. O mundo inteligível de Platão - as formas imutáveis não estão na ideia como esse pensou, mas, para Aristóteles, nas substâncias. Portanto, o sujeito expressa que é, e, por conseguinte, é verdadeiramente; contudo, nos seus predicados notamos também o tempo, a quantidade, o lugar, a posição dentre outras categorias. 
Até aqui, a linguagem sequer foi tocada, nem resolvida, essa questão só terá o primeiro sinal de abalo no horizonte medieval. Em certa medida, a lógica de Aristóteles nada mais é do que a configuração dos entes singulares no plano do universal, numa crença justificada. Por exemplo, podemos afirmar: se todos os homens são mortais, e se João é homem, então João é mortal; ou ainda, podemos afirmar: todo homem é racional, logo, João é racional. Notemos aqui, o que garante o universal é o predicado e não a universalidade. Nessa perspectiva, estamos no plano de uma crença universalmente justificada. As conjecturas, as hipóteses, as proposições e suposições, em grande parte, são meras atribuições, convenções, de predicados, isto é, de atributos a essências universais. No período medieval, a questão dos universais ganhou prestígio entre os filósofos da época, em certo sentido, eles colocaram a metafísica em cheque de uma vez por todas. Se voltarmos a Heráclito, em certo sentido, ele já o teria feito, porém, em seu devir. Assim como Immanuel Kant fez com a razão, levando-a ao tribunal, os nominalistas assim o fizeram com a metafísica.

Os nominalistas opuseram-se tanto a Platão quanto a Aristóteles. Para o primeiro, tudo existe num mundo à parte, tudo que conhecemos, percebemos, deriva de ideias imutáveis. Para Aristóteles tudo deriva das substâncias, mais precisamente, da essência dos entes singulares. Já sabemos que os entes singulares são constituídos por ato, têm potência, têm matéria e forma, e sendo assim, são considerados também universais. Sem dúvida, se abstrairmos como pensou Aristóteles, nada nos resta senão a essência.

Os maiores expoentes dos representantes dos universais foram Guilherme de Champeaux (1070-1121) e Pedro Aberlado (1079-1142). A relação entre linguagem e realidade é a principal investigação da questão dos universais. Até então a metafísica abarcava a seguinte concepção, que necessário "[...] assegurar de todos os modos o universal in re e, portanto, a permanência e a imutabilidade estrutural de um universo estático, no qual o fluir e o variar de todas as coisas são apenas acidentais e fenomênicos" (REALE, ANTISERI, 1990 p, 521). Isso significa afirmar que os universais são reais, portanto, os entes, apesar das formas diferentes e distintas, são universais. Guilherme e Aberlado se opuseram, escreve Reale e Antiseri a tese dos dois universalistas:

\footnotetext{
Se uma idêntica essência, embora se revestindo de formas diversas, existe nos sujeitos singulares, é necessário que a essência que assumiu outras formas seja aquela mesma essência que assumiu outras formas, de modo que o animal que possui a forma racional seja o mesmo animal formado pela irracionalidade, mas assim o animal racional seria ao mesmo tempo irracional, com consequência de que teríamos a simultaneidade dos contrários no mesmo sujeito. (1990, p.521)
}

Por sua vez, Guilherme de Ockham afirmou várias vezes e sem vacilo, conforme evidenciam os estudos de Antiseri e Reale (1990), na visão de Ockham, o universal não é uma questão real. Para Ockham, existe uma profunda contradição. Os filósofos explicam que essa questão está exatamente em saber se os universais são coisas ou simplesmente nomes. 
Aqui está definitivamente aberta a questão da linguagem no campo da filosofia. Podemos ler, na obra: História da Filosofia Antiguidade e Idade Média de Giovani Reale e Dario Antiseri:

\begin{abstract}
Nenhuma coisa externa à alma, nem por si mesma, nem por outra causa real ou simplesmente racional que se lhe acrescente, nem por qualquer forma que se a considere ou entenda, é universal, pois é tal a impossibilidade que uma coisa externa a alma seja universal quanto é impossível que, sob qualquer consideração ou sob qualquer aspecto, o homem seja asno. A realidade universal, portanto, é contraditória, devendo ser total e radicalmente excluída. A realidade é essencialmente individual. Os universais são nomes, não realidade, nem algo com fundamento na realidade. $E$ Ockham precisa: 'No indivíduo não há nenhuma natureza universal realmente distinta daquilo que é próprio de um indivíduo. Porque 'ou ela faz parte de um mesmo indivíduo e nesse caso não pode ser distinta dele ou então permanece distinta do indivíduo e este poderia evidentemente existir sem aquela natureza. A realidade, portanto, é toda singular. (1990, p.619).
\end{abstract}

Desta forma, é proposto o primeiro problema ostensivo à linguagem. Os nominalistas desmantelaram e destronaram a tese que o homem é um ser racional, no momento que o predicado racional é atribuído ao universal, com isso, o debate afunilou-se. A fundamentação de Ockham resvalou no mundo da escolástica cristã e não foi bem aceita. A navalha de Ockham cortou pelo meio as bases e toda a suspenção da metafísica: o ser não existe, aliás, existe somente no nome! Assim ficou conhecida a famosa navalha: não se multiplica os entes sem necessidade - "Entia non sunt multiplicanda praeter necessitatem". (REALE; ANTISERI, p.621). Mas, os nominalistas foram banidos. Para que a tese nominalista sobrevivesse dependeria da aceitação ou não de seus pressupostos, em outros termos, a escolástica teria que aceitar a inexistência ontológica das essências universais. Notemos então, tudo é simplesmente uma questão de escolha, de convenção, de gosto, de crença. Se os medievais não puderam provar a inexistência dos pressupostos nominalistas, da mesma forma, não puderam demonstrar o contrário. Se a filosofia deveria partir da distinção entre a opinião verdadeira (doxa) e o conhecimento (epistéme), conforme pensou Platão, então a trilha dos limites e possibilidades do conhecimento, historicamente determinada, não passava de uma crença justificada pela civilização ocidental. Podemos ler exatamente isso no diálogo entre os personagens de Platão, Mênon e Sócrates:

SO. - Mas se alguém, tendo uma opinião correta sobre qual é o caminho, mas jamais o tendo percorrido nem tendo dele a ciência, < partisse e guiasse outros>, este também não guiaria corretamente? MEN - Perfeitamente. SO. - E, penso, que pelo menos enquanto tiver a opinião correta sobre as coisas de que o outro tem a ciência, acreditando com verdade embora não compreendendo, não será em nada um guia inferior àquele que compreende isso. (PLATÃO, 2001, p.99).

Na tentativa da distinção entre a opinião e o conhecimento, Platão, em certo sentido, propõe uma noção de conhecimento validado por uma crença supostamente verdadeira. Notemos aqui, esta definição de conhecimento está fundada no conceito, logo, na proposição. Se a filosofia queria ir para ir além do senso comum, então, parece ter perdido 
sua trilha, ou, mais que isso, nunca a encontrou. O horizonte da Idade Moderna, no âmbito filosófico, é inicialmente guiado por Renê Descartes, ele demarca a linha tênue entre filosofia e ciência, e os filósofos Francis Bacon (1561), John Locke (1632-1704) e David Hume (17111776) demarcam o território empirista, cada qual a seu estilo. Hume, em Ensaio sobre o Entendimento Humano, destrona a ideia de causalidade, deixando a conjuntura cada vez mais embaraçante:

Entretanto, embora nosso pensamento pareça possuir esta liberdade ilimitada, verificaremos, através de um exame mais minucioso, que ele está realmente confinado dentro de limites muito reduzidos e que todo poder criador do espírito não ultrapassa a faculdade de combinar, de transpor, aumentar ou de diminuir os materiais que nos foram fornecidos pelos sentidos e pela experiência. Quando pensamos numa montanha de ouro, apenas unimos duas ideias compatíveis, ouro e montanha, que outrora conhecíamos. (2006, p.11).

Para Hume, o conhecimento não se dá pelas causas, mas pela contiguidade, ou seja, pelos nexos de contiguidade. O conhecimento, para Hume, é um hábito. Podemos assim expressar, é um momento de tormenta teórica. O desinteresse pela metafísica é crescente, ao contrário, os problemas passam a ter uma dimensão gnoseológica - conhecimento, política e ética ganham destaque. Neste descompasso histórico e conceitual, algumas escolas de filosofia buscam um novo caminho para esse mover filosófico, caminho que só poderia ser original, enquanto caminho da linguagem. Escreve Wittgenstein em Tractatus:

O homem possui a capacidade de construir linguagens nas quais cada sentido se deixa exprimir, sem, contudo, pressentir como e o que cada palavra denota - Assim se fala sem saber como os sons singulares são produzidos. A linguagem forma parte do organismo humano e não é menos complicada do que ele. É humanamente impossível de imediato apreender dela a lógica da linguagem. (TL, 4.0002, 1968, p.70)

O interesse desse excêntrico e genial filósofo austríaco se direciona para o mundo da linguagem. Para ele, a linguagem é uma forma de vida. A linguagem, para Wittgenstein (1968), faz parte do organismo humano e é tão complicada como esse: "A maioria das proposições e questões escritas sobre temas filosóficos não são falsas, mas absurdas." (TL 4003,1968, p.70). Isso não vale tão-somente para a filosofia. Nesse momento do primeiro Wittgenstein, a totalidade das proposições é a linguagem, o homem constrói a linguagem, isto é, ele é capaz de criá-la, de certo modo, de inventá-la ou, mais especificamente, consegue exprimir seus pensamentos, no entanto, não consegue, "[...], contudo pressentir como e o que cada palavra denota. Assim, se fala sem saber como os sons singulares são produzidos." (TL 2002, 1968, p. 70). A partir do primeiro Wittgenstein, a análise wittgensteiniana aprofunda o horizonte da filosofia da linguagem para fazer oposição às correntes idealistas de sua época. As principais opções filosóficas para ele derivam da análise descritiva de Russell, como da análise do sentido e da referência de frege. 


\section{O HORIZONTE DA LINGUAGEM EM WITTGENSTEIN}

A preocupação com a linguagem na civilização ocidental moderna ganhou uma conotação distinta, essa não é somente uma programação das instituições do conhecimento, das academias, das artes, das letras, da psicologia. Não é uma inquietação epistemológica da filosofia ou das humanidades, nem somente das ciências, da política, da mídia e do poder empresarial. Do ponto de vista do saber, a frase de Aristóteles se torna enfadonha no mundo filosófico, no entanto, ela continua sendo original: "Todos os homens, por natureza, desejam saber [...]". (ARISTÓTELES, 2005, p.86). Isso significa que o conhecimento está longe de ser um instrumento apenas da filosofia ou das ciências, é de todos, em suma, é um bem público. E por essa razão, nós, homens e mulheres das ciências, das humanidades, não temos direito de arrogar sua posse como um bem privado. Ludwig Wittgenstein analisa seu sentido público.

Conforme afirmamos, desde os pré-socráticos até os nossos dias, a filosofia logrou ser a detentora desse conhecimento e, em certo sentido, entrelaçou e escondeu a trama e a lógica da dinamicidade da linguagem num simulacro aparentemente metafísico historicamente determinado. É sobre isso que Deleuze e Guattari insistiam quando afirmaram sobre o desandar conceitual moderno. Para eles, existe um descompasso intelectual: "Pedimos somente que as nossas ideias se encadeiem segundo um mínimo de regras constantes [...]" (2004, p.259). E é isso que faz Wittgenstein, sua investigação volta constantemente para investigar como a linguagem funciona. Enfatiza o filósofo austríaco: "[...] os problemas filosóficos nascem quando a linguagem entra em férias [...]." (IL, 23, 1999, p. 42). E, é também isso que percebemos: quando perdemos o sentido elucidativo e formativo da linguagem, nem filosofia e nem linguagem ou a ciência atingem sua finalidade. Para Wittgenstein a questão não está em descobrir o significado da linguagem, mas, seu uso. "Quando a criança aprende essa linguagem, deve aprender a série dos numerais a, b, c de cor, e deve aprender seu uso" (IL, 9 1999, p.30.). Wittgenstein, assim como todos os filósofos analíticos, parte do seguinte pressuposto: o que está em causa não é a verdade ou o caminho que ela é conduzida, uma coisa é certa para eles: a verdade não pode surgir de crenças. Expressa Gonzáles:

[...] a hora bien, la certeza no se consigue con la simple certidumbre, sino que es necesaria la seguridad: algo es verdadero no cuando opinamos que lo es, ni cuando creemos que lo es, sino cuando podemos estar seguros de que efectivamente lo es, es decir, cuando es cierto que lo es, cuando necesariamente es lo que es. (2011, p.4)

Para além da certeza, a filosofia, as ciências, necessitam de segurança, sobretudo de uma conotação elucidativa. Mas, qual a segurança que terá uma linguagem repleta de irracionalidades? No centro desse descompasso intelectual das proposições, ou propriamente, de conhecimento propositivo, o que pode ser uma frase falsa, ou quando ela é verdadeira? Os lógicos como Gottob Frege e Bertrand Russell, dentre outros, utilizaram um símbolo específico (' '), antes de escreverem as proposições, supostamente ditas falsas ou verdadeiras. Para 
entender isso com um pouco mais de clareza, Abbagnano lembra-nos que, ainda na Idade média "[...] a lógica terminista medieval julgava, porém, que as expressões "é verdade que 'p'” e 'p', (onde 'p' é sinal de uma proposição) devem ser consideradas sinônimas." (2000, p. 84). Frege e Russell desencadeiam a questão gramatical e lógica da linguagem, a qual, posteriormente, Wittgenstein complementa com determinação. Por sua vez, Frege, da tradição da semântica, é considerado o inspirador primeiro dessa corrente; expressa Marcondes, ele é "[...] um dos maiores lógicos do período contemporâneo [...]" (2004, p. 18.). Este mesmo autor enfatiza que podemos encontrar no ultimo quartel do século dezenove uma tentativa de romper com o psicologismo e também contra uma teoria epistêmica fundamentada na produção do conhecimento. Frege contrapõe a isso com a sua teoria de sentido e referência. Sua tese, como afirmamos, é uma reação conjunta contra as teorias de Immanuel Kant (1742 - 1804), Gottfried Leibniz (1646 - 1716) e John Stuart Mill (1806 - 1873). Frege quer, sem dúvida, fazer a distinção entre o objeto de conhecimento e seu reconhecimento. Ele descarta o psicologismo subjetivista onde a mente produziria o conhecimento, ao mesmo tempo, rejeita o objetivismo realista, ou seja, onde a realidade teria em si a capacidade de prover logicamente formar abstratas das entidades. Frege analisa as sentenças no seu significado, não do ponto de vista psicológico e subjetivo. Por sua vez, Bertrand Russell, nesta mesma trilha propõe uma análise lógica das sentenças ou das asserções. Escreve Danilo Marcondes:

\begin{abstract}
A teoria das descrições de Russell parte da concepção de que a forma gramatical das sentenças não representa sua forma lógica que revele ou torne explicita essa forma lógica. [...] O problema surge quando consideramos expressões que não possuem uma referência ou denotação. [...] O exemplo clássico é a análise que Russell submete a sentença S: 'O atual rei de França é careca. ' Uma vez que não existe um Rei de França, a sentença não pode ser considerada verdadeira. Porém, tampouco é falsa, pois não podemos dizer que o atual rei da França não é careca. Também não podemos considerá-la sentido, uma vez que pode ser perfeitamente compreendida.
\end{abstract}

Podemos perceber que a sentença está violando o princípio do terceiro excluído, ou seja, cujo enunciado é: ou João é x ou é y, não pode haver uma terceira possibilidade. Portanto, nessa sentença, o princípio foi abalado. Somente uma análise lógica poderá resolver este problema. Isso é o que Russell compreendeu. Salientamos aqui: a teoria de Bertrand Russel vai além desta simples demonstração, apenas situamos inicialmente o problema para introduzir as análises de Wittgenstein e, a partir destas primeiras e rápidas abordagens teóricas de Frege e Russell, Wittgenstein inicia sua instigante jornada lógica no mundo da linguagem. Em suas análises (IF 309, 1990, p.309) ele confirma a finalidade da linguagem na filosofia que é "- Mostrar à mosca a saída da garrafa." Nesse contexto, a filosofia que, em certo sentido, esteve presa, travada, colada no mundo da essência, do psicologismo, da metafísica, da história, expressa ele o Tractatus:

Toda filosofia é crítica da linguagem. (Por certo, não no sentido de Mauthner) O mérito de Russell é ter mostrado que forma aparentemente lógica da proposição não deve 
ser sua forma real. A proposição figuração da realidade. A proposição é modelo da realidade tal qual como a pensamos. À primeira vista, a proposição - em particular tal como está impressa no papel - não parece ser afiguração da realidade de que se trata. Mas tão pouco a escrita musical parece ser à primeira vista ser afiguração da música, e nossa escrita fonética (letras) figuração da linguagem falada. (4.0031 - 4011, 1968, p.71).

Quando Wittgenstein escreve que a proposição é figuração da realidade significa que as sentenças, as figuras, os nomes, os escritos, de fato, figuram a realidade, ou seja, nada disso é realidade tal e qual. Por sua vez, o conceito não é a realidade. Anteriormente, já expusemos em certo sentido o problema do nominalismo, os medievais em grande parte acreditavam que o significado dos conceitos, dos nomes, ou, mais especificamente, que o significado da palavra se referia ao mundo sensível - isto é, aquele que se manifesta diante de nós. Isto, para grande parte dos filósofos medievais, se verificava e se assentia como conhecimento verdadeiro. Como já estudamos na primeira parte deste artigo, em Platão, a linguagem estava num mundo superior, isto é, fora do sensível. Para Aristóteles, a linguagem, as frases, as proposições as asserções, as sentenças, a escrita, a locução são categorias, símbolos, comparações da natureza da alma. Em Da Alma, o Estagirita, explica o sentido, a percepção, a imaginação, o intelecto, o conhecimento e todas as categorias que pertencem à alma. "É necessário, por conseguinte, que a alma seja a substância, no sentido de forma de um corpo natural que possui a dinâmica da vida" (2001, p.52). Portanto, a alma a chama, evoca através das imagens os conceitos, as palavras, em sentido psicológico, poderemos concluir que alma humana tem por objeto a substância e suas determinações categóricas.

E assim, por muitos séculos a linguagem permaneceu muda. Wittgenstein procurou encontrar a linguagem nas sombras do silêncio metafísico. A linguagem não pode ser essencialista, fundamentalista, psicologista, normativa, declarativa, nominalista. Ele detona toda a forma de linguagem fixa, travada, presa, logo, percebeu que a linguagem disfarça, veda, engana, e é privativa, portanto, autoritária. Ela é um jogo. A noção de jogo em Wittgenstein não é pronta e nem acabada. Jogo é aquilo que se joga, não tem previsibilidade. Por isso, a importância da reflexão filosófica, para ele, a filosofia "[...] é esclarecimento lógico dos pensamentos." (TL 4.112,1968, p.77). Isso em si é elucidativo e formativo! Decididamente, nossos pensamentos são como nuvens, vão e vem. Logo, "A filosofia não resulta em 'proposições filosóficas', mas em tornar claras as proposições." (TL 4112, 1968, p.76). Mais que isso, a tarefa dela é "[...] tomar os pensamentos que, por assim dizer, são vagos e obscuros e torná-los claros e bem delimitados." (TL 4112, 1968, p.77.) No primeiro Wittgenstein, seu pensamento sobre a finalidade da filosofia é claríssimo. A filosofia deverá demarcar o mundo das ciências naturais com rigor, ao mesmo tempo demarcar a linha do impensável a partir do pensável. No sétimo aforismo, do Tractatus, o último, o mais famoso, o mais conhecido e tão mal interpretado, Wittgenstein afirma: "O que não se pode falar, deve-se calar.". 


\section{CONSIDERAÇÕES FINAIS}

Para melhor esclarecer a conotação formativa que ele conferiu à linguagem, voltemos ao início do Tractatus, no primeiro aforismo ele afirma, "O mundo é tudo que ocorre", ainda, na sequência do primeiro aforismo ele esclarece que é no mundo que tudo acontece. $\mathrm{E}$, o que acontece são os fatos, logo, o mundo é determinado pelos acontecimentos - fatos e, a totalidade desses é o que determinam o mundo. Ele parte do mundo, dos fatos. E é ali que acontece tudo: tudo é determinado ali, e não longe, num mundo à parte. Enfatizamos novamente, isso é formativo e elucidativo em si. Explica ele "Para conhecer um objeto não devo, com efeito, conhecer suas propriedades externas - mas todas as internas." (IL 20123, 1968, p.56). Acrescenta ele: "Ao serem dados todos os objetos, dão se também todos os possíveis estados de coisas." (20124, 1968, p.56.). Notemos aqui, já referendamos anteriormente, o mundo é, para ele, tudo o que ocorre e, tudo que ocorre é a totalidade dos fatos, "[...] logo, o que ocorre, o fato, é o subsistir de um estado de coisas." (TL 2011, 1968, p.55). Então para conhecer o objeto é necessário compreender a realidade inteira, que, para Wittgenstein, é o mundo. Nesta mesma conexão de raciocínio, Austin em Philosophical Papers, entende que, a própria expressão fato não pode inverter a ordem das coisas, "[...] in terms of the expression 'fact that' is to invert the real order of things-just. [...]." (1970, p.164.). Tal qual o pensamento wittgensteiniano, em outros termos, é preciso fazer figurações dos fatos e já sabemos, a figuração nada mais é do que um molde, um modelo da realidade. Na figuração seus elementos correspondem ao objeto. "O nome denota o objeto, o objeto é a sua denotação." (TL322, 1968, 63). Tal como Frege ou Russell, para distinguir um objeto de conhecimento e seu reconhecimento, Wittgenstein não faz metafísica, não faz psicologismo, nem realismo abstrato. Ele não busca compreender o ser e seus entes, também não busca conhecer a mente e suas artimanhas, mas procura na filosofia um caminho seguro! Este caminho não pode ser outra coisa senão a linguagem! Sabe ele muito bem que os pensamentos vagueiam no mundo, entrelaçam na mente, escapa ao controle. Por isso, no segundo Wittgenstein, mais precisamente em Investigações Filosóficas, refere-se à linguagem como uma forma de vida entrelaçada aos jogos da linguagem. Os jogos de linguagem não são, senão, uma pluralidade e um conjunto de frases com os mais distintos empregos, sejam em frases afirmativas ou em frases interrogativas, ou ainda, em frases de comando. Afirma ele: "É interessante comparar a multiplicidade das ferramentas da linguagem e seus modos de emprego, a multiplicidade das espécies de palavras e frases com aquilo que os lógicos disseram sobre a estrutura da linguagem." (IL, 23, 1999, p.36). Sobre toda essa pluralidade ele assevera: "[...] nada é fixo [...]." (IL 23, 1999, p, 35.) Os jogos de linguagem vão e vem, aparecem e desaparecem, uns morrem, outros brotam. Escreve ele: "[...] deve aqui salientar que o falar da linguagem é uma parte de uma atividade, ou de uma forma de vida." (IF 23, 1999, p.35). Portanto, está no mundo, é um fato. Logo, o termo de linguagem ou a variedade de jogos de linguagem são 
múltiplos, variados, ele explica e, quando a linguagem perde sua finalidade, ou seu caráter elucidativo, educativo; só existem embaraços.

Acredita-se que o aprendizado da linguagem consiste no fato de que se dá nomes aos objetos: homens, formas, cores, dores, estados de espírito, números etc. Como foi dito - o de denominar é algo análogo a pregar uma etiqueta numa coisa. Pode chamar isso de preparação para o uso de uma palavra. (IL 26, 1999, p.36.).

Wittgenstein sabe perfeitamente bem que tudo isso não passa de um jogo e que é necessário compreender esse jogo. Nesse sentido, as palavras são axiomas - verdades prontas, que Wittgenstein compara a um jogo. Bem no início das Investigações Filosóficas, ele cita a estrutura axiomática feita em Confissões, quando Agostinho expressa:

\begin{abstract}
Retinha tudo na memória quando pronunciavam o nome de alguma coisa, e quando, segundo essa palavra, moviam o corpo para ela. Via e notava que davam ao objeto, quando o queriam designar, um nome que eles pronunciavam. Esse querer era-me revelado pelos movimentos do corpo, que são como que a linguagem natural a todos os povos e consiste na expressão da fisionomia, no movimento dos olhos, nos gestos, no tom da voz, que indica a afeição da alma quando pede ou possui e quando rejeita ou evita. Por este processo retinha pouco a pouco as palavras convenientemente dispostas em várias frases e frequentemente ouvidas como sinais de objetos. Domando a boca segundo aqueles sinais, exprimia por eles as minhas vontades. (1987, p.16.).
\end{abstract}

$\mathrm{Na}$ tradução que Wittgenstein elaborou da versão alemã de Confissões de Agostinho, a imagem da linguagem ou dos axiomas de Agostinho encontra-se nas raízes da ideia - isto é, cada palavra tem uma significação precisa! A filosofia para Wittgenstein nunca é uma doutrina, mas uma atividade. Referindo-se a Agostinho, ele afirma: "Nestas palavras temos, assim me parece, uma determinada imagem da essência de linguagem humana. $A$ saber, esta: as palavras da linguagem denominam os objetos" (IL 1990, p.27). Uma análise próxima a de Wittgenstein é a de John Austin, em sua obra Sentido e Percepção o filósofo lógico escreve:

Não existe uma maneira simples de livrar-se dessas ilusões - em parte porque, como veremos não existe um 'argumento' simples. Temos uma massa de falácias sedutoras (verbais, na maior parte), e é preciso desenredá-las uma a uma e dar a conhecer uma grande variedade de motivos ocultos - uma operação que, em certo sentido, nos deixa no ponto em que começamos. (2004, p.5).

O processo de aclaramento do uso da linguagem, diferentemente do Tractatus, tem uma posição não fixa da estrutura dos axiomas da linguagem. Assim, é possível "[...] imaginar em $(2)^{2}$ é um daqueles jogos por meio do qual as crianças aprendem sua língua

2 Aquele conceito filosófico da significação cabe bem numa representação primitiva da maneira pela qual a linguagem funciona. Mas, pode-se também dizer, é a representação de uma linguagem mais primitiva do que é a nossa. Cf. WITTGENSTEIN, Ludwig. Investigações filosóficas. (IL 2, 1990, p.28.). 
materna. Chamarei esses jogos de 'jogos de linguagem' e falarei muitas vezes de uma linguagem primitiva como um jogo de linguagem." (IF 7, 1999, p.30.). A questão é de fundo cultural, o exemplo clássico é o caso da lajota que Wittgenstein elucidou. Se um indivíduo tal, ou seja, se (A) sabe que 'x' é '@'; e outro indivíduo (B) não sabe que 'x' é '@' numa cultura determinada, não existe comunicação nem aprendizado. Ou seja, se (B) não sabe que 'lajota, pode ser tijolo', logo, impossível compreender os jogos de linguagem, assim permanece o bloqueio. A lajota em determinada cultura pode expressar pedra, mas em outra cultura pode expressar tijolo. Essa reflexão pode parecer bastante simples, porém seu alcance nos jogos de linguagem perpassa uma multiplicidade de equívocos, enganos em determinada cultura. Por isso Wittgenstein afirmou que a linguagem veda, disfarça o pensamento, a linguagem engana, a linguagem veta, a linguagem amarra e, portanto, trava seu uso. George Edward Moore (1873 - 1958) em 1921 escreveu o seguinte, em seu estudo na ocasião da Herzt Lecture do Professor Stout, sobre Procceeding of the Britist Academy, expressa Moore:

\begin{abstract}
Ele defende aí uma perspectiva, que ele parece pensar que se pode expressar apropriadamente pelas palavras: 'todo caráter que caracteriza ou uma coisa concreta ou um indivíduo concreto é particular e não universal'. Entendo que o que se requer que façamos é discutir a tese em que ele expressa por essas palavras. Não devemos atribuir às palavras o sentido ou sentidos que nós mesmos pensamos que elas devem transmitir, e seguir a discutir se a perspectiva ou as perspectivas que elas expressariam então são verdadeiras ou falsas. O que devemos fazer é tentar descobrir o que em que ele as emprega para expressá-las é verdadeiramente é verdadeiramente falsa ou verdadeira, ainda que possamos pensar que a expectativa em questão é uma perspectiva que elas não podem de modo algum expressar apropriadamente. (1995, p.69)
\end{abstract}

Cada vez mais, a análise wittgensteiniana aprofunda a lógica de uma pragmática fundamental no sentido de dar às frases a sua não rigidez. Nada pode ser fixo. O que até agora foi determinado pela verdade da essência, da metafísica, isto é, na linguagem de Wittgenstein, uma palavra, um nome não têm um significado pronto, acabado, mas, em grande parte são e estão delimitados por regras quase que imperceptíveis. O exemplo mais conhecido é o jogo de xadrez. Novamente utilizando Agostinho de Hipona, expressa ele se referindo a uma criança em seu processo de aprender.

E agora podemos dizer, creio, Santo Agostinho descreve o aprendizado de uma linguagem humana como se uma criança chegasse a um país estrangeiro e não compreendesse a língua desse país; isto é, como se ela já estivesse uma linguagem, só que não usa. Ou também: como se a criança já pudesse pensar, e não pudesse falar. E 'pensar' significaria aqui qualquer coisa como: falar consigo mesmo (IL 1990, p.39.).

Wittgenstein utiliza o jogo de xadrez para explicar as regras do jogo. Por exemplo, o rei, no jogo de xadrez, tem uma função predeterminada e ambos os jogadores sabem disso, tanto o jogador (C) com o (S). O rei é uma peça de jogo, enquanto a palavra para Wittgenstein é uma figura de jogo. Expressa em sua genialidade: "(Uma nuvem inteira condensa numa 
gotinha de gramática)." (1990, p. 2000.). No caso do jogo de xadrez a peça do rei pode ser movida, e os jogadores sabem disso, ele vai para um lado e para o outro, mas em relação às palavras, se, por exemplo, afirmarmos, este é um rei, ou mais especificamente, esse pode ser denominado rei, estamos então, no plano, ou na esfera das elucidações das palavras, por isso Wittgenstein assevera inúmeras vezes, precisamos conhecer as regras que determinam o jogo. Finalizamos com um derradeiro exemplo, o do vaso.

\begin{abstract}
Imagine que alguém aponte um vaso e diga: 'Veja o maravilhoso azul! - não se trata de forma! - Ou: 'Veja a maravilhosa forma! - a cor é indiferente'. Sem dúvida você fará coisas diferentes quando aceder a esses dois convites. Mas você faz sempre o mesmo quando dirige sua atenção à cor? Representem-se então diferentes casos! Quero indicar alguns: ‘Este azul é o mesmo que aquele lá? Vê uma diferença?’ Você mistura as cores e diz! 'Este azul do céu é difícil de obter'. 'O tempo está melhorando, vê-se já o céu outra vez!' 'Veja como são diferentes esses dois tons de azul!' 'Vê ali o tom de azul? Traga o aqui'. 'Este sinal de luz azul significa...' 'Como se chama este azul?' - É indigno? (IL 33, 1990, p.39.).
\end{abstract}

Wittgenstein explica que a grande preocupação filosófica sempre esteve voltada para a forma, seja com gestos, seja com os olhos; expressa ele: '[...] 'apontar a forma', 'ter em mente a forma' etc., não são usadas como estas 'apontar este livro' (e não aquele), 'apontar a cadeira, não a mesa' etc." (IL 36,1990, p.41.). Notemos aqui como aprendemos diferente o uso das palavras. Essa é o esclarecimento de Wittgenstein: por um lado, apontamos este celular, ou apontamos aquele computador, por outro lado, quando apontamos a cor e não a forma, teremos em mente a cor, assim por diante. Assim, ele faz a relação entre o nome e o denominado, e desvenda o jogo linguagem. Por aí podemos encontrar uma pluralidade de comandos, de perguntas, de afirmações, isso são jogos de linguagem, o que está em questão é sempre a forma, se isso acontece no plano do cotidiano tanto e tantas vezes, imaginemos no plano metafísico? A confusão é generalizada! É isso que Wittgenstein investiga e foi tão mal interpretado.

\title{
REFERÊNCIAS
}

AGOSTINHO, Santo. Confissões e de Magistro. Trad. J. Oliveira e A. Ambrósio de Pina. São Paulo: Nova Cultural, 1987.

ARISTÓTELES. Da alma. Trad. Carlos Aberto Gomes. Lisboa: Edições 70, 2001.

ARISTÓTELES. Metafísica. Trad. José Ferreira Borges. Lisboa: Areal Editores, 2005.

AUSTIN, J. L. Philosophical papers. 2 ed. Oxford: At Clarendon Press, 1970. Disponível em: $\quad<$ http://www.spiritual-minds.com/philosophy/assorted/Austin,\%20John\%20-\%20 Philosophical\%20Papers\%202ed\%20-\%20Philosophy\%20of\%20Language.pdf >Acesso em abril de 2016.

Sentido e percepção. Trad. Armando Manuel Mora de Oliveira. São Paulo: Martins 
Fontes, 2004.

DELEUZE, Gilles GUATTARY. O que é filosofia? Trad. Bento Prado Jr. Alberto Alonso Munõs. São Paulo: Editora 34, 2004.

GILSON, Etienne. A filosofia na idade média. São Paulo: Martins Fontes, 2001.

GONZÁLES, Sebastián Salgado. Bertrand Russel: un viaje a los fundamentos de la verdade. Cadernos de Filosofia. DUERERÍAS Septiembre. p. 1-71. 2011. Disponível em: <http://guindo. pntic.mec.es/ssag0007/filosofica/Russell.pdf >Acesso em abril de 2016

HUME, David, Ensaio sobre o entendimento humano 1748. Trad. Anoar Aiex. Fonte Digital, 2006. Disponível em: <http://www.ebooksbrasil.org/eLibris/hume.html> Acesso em maio de 2016.

MARCONDES, Danilo. Filosofia analítica. Rio de Janeiro: Jorge Zahar, 2004.

MOORE, George Edward. Princípios éticos escritos filosóficos, problemas fundamentais de filosofia. Trad. Hugh Lacey. Luiz João Baraauna. Pablo Rubém Mariconda. São Paulo: Abril Cultural, 1995. (Os Pensadores)

NIETZSCHE Friedrich. A filosofia na idade trágica dos gregos. Lisboa: Edições 70, 2009.

PARMÊNIDES. Da natureza. Trad. José Gabriel Trindade Santos. São Paulo, Edições Loyola, 2002. Disponível em: < https://jadirantunes.files.wordpress.com/2014/12/parmc3aanides-deelc3a9ia-da-natureza.pdf > Acesso em agosto de 2021.

PLATÃO. Mênon. Tradução. Maura Iglésias. Rio de Janeiro: Edições Loyola, 2001.

SILVA, Marcio Bolda da. Metafísica e assombro - curso de ontologia. São Paulo: Paulus, 1994.

WITTGENSTEIN, Ludwig. Investigações filosóficas. Trad. José Carlos Bruni. São Paulo: Editora Nova Cultural Ltda. 1999. Disponível em: < https://marcosfabionuva.files.wordpress. com/2011/08/investigac3a7c3b5es-filosc3b3ficas.pdf >Acesso em abril de 2016.

Tractatus logico-philosophicus. Trad. José Arthur Giannotti. São Paulo. Companhia Editora Nacional-Editora da Universidade de São Paulo, 1968. (Filosofia). Disponível em: <https://drive.google.com/file/d/OB2a3UynNKV2CMOlxdVUycjA0SVk/ view> Acesso em agosto de 2021. 